\title{
Vaccination with ubiquitin-hepatitis B core antigen-cytoplasmic transduction peptide enhances the hepatitis B virus-specific cytotoxic T-lymphocyte immune response and inhibits hepatitis B virus replication in transgenic mice
}

\author{
MENG ZHUO, LINLIN SONG, YUYAN TANG, SHENGLAN DAI, XIAOHUA CHEN, \\ YONGSHENG YU, GUOQING ZANG and ZHENGHAO TANG \\ Department of Infectious Disease, Sixth People's Hospital Affiliated to Shanghai Jiao Tong University, \\ Shanghai 200233, P.R. China
}

Received August 1, 2014; Accepted April 28, 2015

DOI: $10.3892 / \mathrm{mmr} .2015 .3834$

\begin{abstract}
Chronic hepatitis B virus (HBV) infection is characterized by functionally impaired type 1 T-helper cell (Thl) immunity and poor HBV-specific T-cell responses. Ubiquitin (Ub), a highly conserved small regulatory protein, commonly serves as a signal for target proteins that are recognized and degraded in proteasomes. The rapid degradation of Ub-mediated antigens results in efficient stimulation of cell-mediated immune responses. Thus, the Ub-HBV core antigen ( $\mathrm{HBcAg}$ )-cytoplasmic transduction peptide (CTP) fusion protein was designed for specific delivery of a foreign modified antigen to the cytoplasm of antigen-presenting cells. HBV transgenic mice were used to determine whether $\mathrm{Ub}-\mathrm{HBcAg}$-CTP would restore $\mathrm{HBV}$-specific immune responses and anti-viral immunity in these animals. The results demonstrated that synthesized Ub-HBcAg-CTP not only significantly increased the levels of interleukin- 2 and interferon (IFN) $-\gamma$ compared with those in the HBcAg-CTP, IFN- $\alpha, \mathrm{Ub}-\mathrm{HBcAg}, \mathrm{HBcAg}$ and phosphate-buffered saline groups, but additionally induced the highest IFN- $\gamma^{+} \mathrm{CD}^{+}$ T-cell numbers and HBV-specific cytotoxic T lymphocyte (CTL) responses, indicating a strong immune response. In addition, enhancement of specific CTL activity provoked by the fusion protein reduced hepatitis B surface antigen ( $\mathrm{HBsAg}$ ) and HBV DNA serum levels and diminished the expression of $\mathrm{HBsAg}$ and $\mathrm{HBcAg}$ in liver tissue of HBV transgenic mice, suggesting that there was a therapeutic effect. In conclusion,
\end{abstract}

Correspondence to: Professor Zhenghao Tang, Department of Infectious Disease, Sixth People's Hospital Affiliated to Shanghai Jiao Tong University, 600 Yishan Road, Shanghai 200233, P.R. China E-mail: tzhhao@163.com

Key words: ubiquitin, cytoplasmic transduction peptide, hepatitis B virus core antigen, hepatitis B virus transgenic mice, cytotoxic T lymphocytes, virus immunotherapy the present study provided evidence that Ub-HBcAg-CTP activated the Th1-dependent immunity, triggered functional $\mathrm{T}$ cell responses and subsequently inhibited viral replication in HBV transgenic mice. These observations suggested that the fusion protein may represent an innovative and promising candidate for active immunotherapy during chronic and persistent HBV.

\section{Introduction}

Hepatitis B virus (HBV) infection remains to be a serious health problem worldwide (1). Carriers of $\mathrm{HBV}$ are at increased risk of developing cirrhosis and hepatocellular carcinoma (HCC), with an estimated 563,000 mortalities annually worldwide from cirrhosis and HCC (2). Increasing evidence suggests that host-immune responses are important in determining the outcome of HBV infection (3). Acutely infected individuals typically develop a strong, multispecific cytotoxic T-lymphocyte (CTL) response and a polyclonal T-helper (Th) cell response to the virus $(4,5)$, while these responses are weak or undetected in patients with chronic HBV infection (6). Therefore, novel immunotherapeutic approaches are required in order to alter the T-cell response into a predominant Th1 pathway and enhance HBV-specific CTL responses, which may facilitate the eradication of chronic HBV infection.

HBV core antigen ( $\mathrm{HBcAg}$ ) is a peptide that induces strong immune responses characterized by clear T-cell activity in natural and recombinant forms $(7,8)$. Despite the high immunogenicity of exogenous $\mathrm{HBcAg}$, HBV-specific CTL responses induced by simple exogenous $\mathrm{HBcAg}$ are commonly weak, predominantly due to restricted intracellular antigen delivery by the lipophilic and selectively permeable biological membranes (9). The cytoplasmic transduction peptide (CTP) was specifically designed to ensure the efficient delivery of CTP-fused biomolecules into the cytoplasm of cells (10). Increasing evidence has demonstrated that HBV-specific CTL responses are able to become robust, polyclonal and multispecific reactions when exogenous $\mathrm{HBcAg}$ is combined with CTP; such fusion leads HBcAg 
through cellular membranes and into the antigen-presenting cell (APC) cytoplasm $(9,11)$.

The 76-residue polypeptide ubiquitin ( $\mathrm{Ub}$ ) is highly conserved among eukaryotes (12) and covalently binds the majority of proteins destined for degradation by the ubiquitin-proteasome system (UPS) (13). This is critical for the generation of the majority of peptides presented by class I major histocompatibility complex (MHC) molecules $(14,15)$. The modification of antigens by ubiquitin or ubiquitin-like proteins remodels their surface, triggering rapid degradation, thus resulting in increased in vivo CTL responses to the conjugated antigen $(16,17)$. Therefore, Ub has been suggested to be a potential therapeutic target for HBV treatment (18).

There is a possibility for exogenous $\mathrm{HBcAg}$, with the assistance of CTP, to enter the cytoplasm of APCs. When covalently attached to exogenous $\mathrm{Ub}, \mathrm{HBcAg}$ is rapidly degraded and presented by MHC-I molecules, allowing fast and efficient action of CTL against viral infections (19). Consequently, a novel recombinant fusion protein, $\mathrm{Ub}-\mathrm{HBcAg}-\mathrm{CTP}$, was developed in the present study. Of note, Ub-HBcAg-CTP was able to enter the cytoplasm of dendritic cells (DCs) and elicit robust specific HBV immune responses in vitro (data not shown). The present study aimed to assess whether the Ub-HBcAg-CTP fusion protein were able to improve $\mathrm{HBV}$-specific CTL immune responses and anti-viral immunity in $\mathrm{HBV}$ transgenic mice.

\section{Materials and methods}

Fusion proteins and cell culture. The plasmid pcDNA3.1(-)-Ub-HBcAg was constructed and maintained in the Laboratory Centre of The Sixth Hospital affiliated to Shanghai Jiao Tong University (Shanghai, China) (11). Briefly, the Ub-HBcAg cDNA sequence was generated via polymerase chain reaction (PCR) to obtain an 820 bp PCR product. The Ub-HBcAg-CTP gene and other control genes, Ub-HBcAg and HBcAg-CTP, were amplified via PCR and inserted into the pMAL-c2X prokaryotic expression vector (Invitrogen Life Technologies, Carlsbad, CA, USA), respectively. The constructed plasmids were further identified by restriction enzyme digestion and bidirectional DNA sequencing (New England Biolabs, Ipswich, MA, USA). Subsequently, the recombinant plasmids were transformed into the host Escherichia coli BL21 (DE3) cells (Tiangen, Beijing, China), which were induced to express the recombinant fusion proteins. All fusion proteins were analyzed via western blot analysis.

$H B V$ transgenic mice and immunization. HBV transgenic mice ( $\mathrm{n}=42$; weight, 22-28g), BALB/c-HBV1.3 (ayw subtype), which contained the 1.3-fold over-length HBV genome, were purchased from the Key Liver Army Laboratory (458 Hospital, Guangzhou, China). The mice were maintained in $12 \mathrm{~h} \mathrm{light/dark} \mathrm{cycles} \mathrm{at} \mathrm{a} \mathrm{temperature} \mathrm{of} 20-25^{\circ} \mathrm{C}$, with free access to food and water. The detailed characterization of these mice has been described previously (20). Groups of mice in all experiments were matched for age (6-8 weeks; female) and all animals were housed in the experimental animal centre of the Sixth Hospital affiliated to Shanghai Jiao Tong University (Shanghai, China) under specific pathogen-free conditions. All experiments were approved by the Laboratory Animal Ethics Commission of Shanghai Jiao Tong University (Shanghai, China). Mice were allowed 1 week of adaptation and randomly divided into six groups $(n=7)$. Subsequently, the animals were immunized intramuscularly in the tibialis anterior muscle three times at 1-week intervals with Ub-HBcAg-CTP $(50 \mu \mathrm{g})$, HBcAg-CTP $(50 \mu \mathrm{g})$, Ub-HBcAg $(50 \mu \mathrm{g})$ and interferon (IFN)- $\alpha$ (20,000 IU; Roche Diagnostics, Basel, Switzerland), HBcAg (50 $\mu \mathrm{g}$; CalBioreagents, Inc., San Mateo, CA, USA), or phosphate-buffered saline (PBS; $50 \mu$ l; Youkang, Beijing, China). At 1 week subsequent to the last immunization, the mice were sacrificed by cervical dislocation following anasthesia with $3 \%$ pentobarbital sodium (Sigma-Aldrich, St. Louis, MO, USA), via intramuscular injection, and serum samples, splenocytes and livers were collected.

Intracellular cytokine staining in splenic lymphocytes. HBV transgenic mouse spleens were extracted for splenocyte collection, by grinding of the spleens. T-lymphocytes were obtained from splenocytes using nylon wool columns (Polysciences Europe GmbH, Eppelheim, Germany). To evaluate the percentage of IFN- $\gamma$-secreting cells in mouse splenocytes, single-cell suspensions of harvested $\mathrm{T}$ cells were analyzed by flow cytometry (Beckman Coulter, Inc., Brea, CA, USA). Following incubation with $10 \mu \mathrm{g} / \mathrm{ml} \mathrm{HBcAg}$ for $3 \mathrm{~h}, 25 \mu \mathrm{g} / \mathrm{ml}$ phorbol 12-myristate 13-acetate (PMA; Sigma-Aldrich), $1 \mu \mathrm{g} / \mathrm{ml}$ ionomycin (Sigma-Aldrich) and $1.7 \mu \mathrm{g} / \mathrm{ml}$ monensin (Sigma-Aldrich) were added to spleen Tlymphocytes for another $3 \mathrm{~h}$ (21). The cells were then washed with PBS and stained with saturating concentrations of phycoerythrin (PE)/Cy5-conjugated anti-CD3 mouse monoclonal antibody (0.2 mg/ml; cat. no. 15-4888; eBioscience, Inc., San Diego, CA, USA) and fluorescein isothiocyanate-conjugated anti-CD $8 \alpha$ mouse monoclonal antibody (0.2 $\mathrm{mg} / \mathrm{ml}$; cat. no. 11-0081; eBioscience, Inc.) for $30 \mathrm{~min}$ at $25^{\circ} \mathrm{C}$. Subsequent to fixation/permeabilization with Fix and Perm reagent A and B (BD Biosciences, Franklin Lakes, NJ, USA), cells were incubated with PE-labeled anti-IFN- $\gamma$ mouse monoclonal antibody $(0.2 \mathrm{mg} / \mathrm{ml}$; cat. no. 12-7311; eBioscience, Inc.) for $30 \mathrm{~min}$ at $25^{\circ} \mathrm{C}$, washed twice with PBS and analyzed by flow cytometry on the Epics XL Flow Cytometer (Beckman Coulter, Inc., Brea, CA, USA) using Expo 32-ADC software (Beckman Coulter).

ELISA. For detection of interleukin (IL)-2 and IFN- $\gamma$, spleen $\mathrm{T}$ lymphocytes $\left(2 \times 10^{6}\right.$ cells $\left./ \mathrm{ml}\right)$ harvested from immunized transgenic mice were cultured in 24 -well plates $\left(1 \times 10^{6}\right.$ cells/well) at $37^{\circ} \mathrm{C}$ in the presence of $10 \mu \mathrm{g} / \mathrm{ml} \mathrm{HBcAg}$. Subsequent to $72-\mathrm{h}$ incubation, the cytokine levels in cell supernatants were assessed using commercial mouse cytokine (IL-2 and IFN- $\gamma$ ) ELISA kits (R\&D Systems, Inc., Minneapolis, MN, USA), according to the manufacturers' instructions. Results were expressed in $\mathrm{pg} / \mathrm{ml}$.

Enzyme-linked immunospot(ELISPOT) assay. The ELISPOT assay (22) was used to evaluate HBcAg-specific IFN- $\gamma$ secretion in splenocytes. Spleen T lymphocytes $\left(1 \times 10^{5}\right.$ cells/well pulsed with $10 \mu \mathrm{g} / \mathrm{ml} \mathrm{HBcAg}$ ) were seeded in triplicate and incubated at $37^{\circ} \mathrm{C}$ for $20 \mathrm{~h}$. A positive control (phytohemag- 
glutinin; 15 mg/ml; Dakewe Biotech Co., Ltd., Shenzhen, China) and a 'non-peptidic' negative control were included in all assays (i.e. wells containing only medium). Following incubation, cells were removed and ImmunoSpot plates (Dakewe Biotech Co., Ltd., Shenzhen, China) pre-coated with the anti-IFN- $\gamma$ monoclonal antibody (BD Biosciences) were processed according to the manufacturer's instructions. The number of spots was counted using the Bioreader 4000 PRO-X (Bio-Sys GmbH, Karben, Germany). Exclusively brown-colored spots with 'fuzzy borders' were scored as spot-forming cells.

CTL assay. P815/c cells (Laboratory Centre of The Sixth Hospital affiliated to Shanghai Jiao Tong University, Shanghai, China) used as target cells, were seeded at a density of $5 \times 10^{4}$ cells/well in 96 -well plates. The spleen $\mathrm{T}$ lymphocytes $\left(5 \times 10^{6}\right.$ cells/well) were used as effector cells and were co-cultured with $\mathrm{P} 815 / \mathrm{c}$ cells at effector/target (E/T) ratios of $5: 1,10: 1$ or $20: 1$, at $37^{\circ} \mathrm{C}$ in a humid environment containing $5 \% \mathrm{CO}_{2}$ for $4 \mathrm{~h}$. The $\mathrm{HBcAg}$-specific CTL activity was measured by lactate dehydrogenase release using a CytoTox $96^{\circledR}$ Non-Radioactive Cytotoxicity kit (Promega Corporation, Madison, WI, USA) according to the manufacturer's instructions. The absorbance values of supernatants were recorded at $490 \mathrm{~nm}$ on an MK3 Multiscan (Thermo Labsystems, Waltham, MA, USA). The cytotoxicity was calculated as follows: [(Experimental release - effector spontaneous release - target spontaneous release) / (target maximum release - target spontaneous release)] x100\% (23).

Serology. Venous blood was collected from transgenic mice at 1 week following the second and third immunizations, respectively. Serum HBV DNA and HBsAg levels were assessed using quantitative PCR (Terra PCR Direct Polymerase mix) and Abbott kits (Abbott Diagnostics, Chicago, IL, USA) separately, as described previously (24). The inhibitory rate of HBV DNA and HBsAg induced by the fusion protein was assessed. In addition, serum alanine aminotransferase (ALT) activities were measured at 7 days subsequent to the third injection using the ARCHITECT Automatic Biochemistry Analyzer (Abbott Diagnostics).

Histology and immunohistochemistry of liver tissues. De-paraffinized $5-\mu \mathrm{m}$ sections were stained with hematoxylin-eosin (Beyotime Institute of Biotechnology, Shanghai, China). For immunohistochemical analysis, slides were incubated for $1 \mathrm{~h}$ at $60^{\circ} \mathrm{C}$ and de-paraffinized. Following antigen retrieval using citrate buffer $(\mathrm{pH}=6.0$; Beyotime Institute of Biotechnology), endogenous peroxidase was quenched by $3 \% \mathrm{H}_{2} \mathrm{O}_{2}$ (Bioworld, Nanjing, China) in deionized $\mathrm{H}_{2} \mathrm{O}$ for $5 \mathrm{~min}$ and non-specific binding blocked by $2 \%$ normal goat serum (Novus Biologicals LLC, Littleton, $\mathrm{CO}$, USA) for $3 \mathrm{~h}$ at room temperature. Samples were then incubated with goat anti-HBsAg polyclonal antibody (Novus Biologicals LLC, Littleton, CO, USA) and goat anti-HBcAg polyclonal antibody (Novus Biologicals LLC) at 1:500 dilutions and $4^{\circ} \mathrm{C}$ overnight, respectively, followed by addition of biotinyated secondary antibody (Wuhan Boster Biological Technology, Ltd., Wuhan, China) at $37^{\circ} \mathrm{C}$ for $30 \mathrm{~min}$ with streptavidin-biotin-peroxidase complex (Biorbyt,
Cambridgeshire, UK). Detection was conducted using diaminobenzidine (Sigma-Aldrich) and cells were counterstained with hematoxylin (20).

Statistical analysis. Values are expressed as the mean \pm standard deviation and all analyses were performed with SPSS software, version 16.0 (SPSS, Inc., Chicago, IL, USA). One-way analysis of variance and the post-hoc least significant difference test were used in order to determine statistical significance. $\mathrm{P}<0.05$ was considered to indicate a statistically significant difference.

\section{Results}

Ub-HBcAg-CTP elicits a robust and functional specific cellular immune response. The specific $\mathrm{CD}^{+} \mathrm{T}$-cell responses induced by the fusion proteins were assessed by intracellular IFN- $\gamma$ staining of T cells isolated 1 week subsequent to the last immunization. Ub fused with $\mathrm{HBcAg-CTP}$, which induced a clear $\mathrm{T}$ cell immune response, displaying the largest number of $\mathrm{CD} 8^{+} \mathrm{IFN}-\gamma^{+} \mathrm{T}$ lymphocytes in the spleens, as detected by flow cytometry. The $\mathrm{CD} 8^{+}$IFN- $\gamma^{+}$ $\mathrm{T}$ cells represented up to $2.2 \%$ of the total spleen $\mathrm{T}$ lymphocytes in mice immunized with Ub-HBcAg-CTP (Fig. 1), compared with $1.7,1.4,1.1,0.3$ and $0.1 \%$ identified in mice that received $\mathrm{HBcAg}-\mathrm{CTP}, \mathrm{IFN}-\alpha, \mathrm{Ub}-\mathrm{HBcAg}, \mathrm{HBcAg}$ and the PBS control, respectively. These observations suggested that delivery of ubiquitin and $\mathrm{HBcAg}$ was mediated via CTP-enhanced HBcAg-specific CTL generation in HBV transgenic mice.

Ub-HBcAg-CTP boosts IFN- $\gamma$ and IL-2 production. One week subsequent to the third intramuscular injection of different fusion proteins, mice exhibited distinct levels of Th1 cell-derived cytokines as detected by ELISA. Fig. 2A and B illustrates the levels of IL- 2 and IFN- $\gamma$ secreted by T cells upon re-stimulation with $\mathrm{HBcAg}$. The highest production of IL-2 $(480.9 \pm 33.7 \mathrm{pg} / \mathrm{ml})$ and IFN- $\gamma(288.2 \pm 16.93 \mathrm{pg} / \mathrm{ml})$ was observed in mice immunized with Ub-HBcAg-CTP.

Ub-HBcAg-CTP enhances the specific CTL response. ELISPOT assays were conducted to quantify the IFN- $\gamma$-producing lymphocytes. A higher percentage of $\mathrm{T}$ cells harvested from Ub-HBcAg-CTP-immunized animals produced IFN- $\gamma$ (Fig. 2C), in comparison with that in the control group. In general, these results were in agreement with the above flow cytometry results for IFN $-\gamma$ expression in $\mathrm{CD}^{+} \mathrm{T}$ cells. Overall, these observations indicated that $\mathrm{Ub}-\mathrm{HBcAg-CTP}$ enhanced HBcAg-specific CTL responses in vivo.

To verify the role of Ub-HBcAg-CTP in cell-mediated immune responses, the cytolytic activity of $\mathrm{HBcAg}$-specific $\mathrm{CD}^{+} \mathrm{T}$ cells was determined by their ability to kill peptide-loaded target cells (P815/c). As presented in Fig. 2D, values of $49.09 \pm 1.44,29.55 \pm 2.01$ and $18.2 \pm 3.26 \%$ for specific cytolysis were obtained for $\mathrm{Ub}-\mathrm{HBcAg}-\mathrm{CTP}$-immunized mice at $\mathrm{E} / \mathrm{T}$ ratios of 20:1, 10:1 and 5:1, respectively. The percentage of specific lysis was significantly higher in mice treated with Ub-HBcAg-CTP than that in animals immunized with other control proteins $\left({ }^{*} \mathrm{P}<0.05\right)$. These observations 


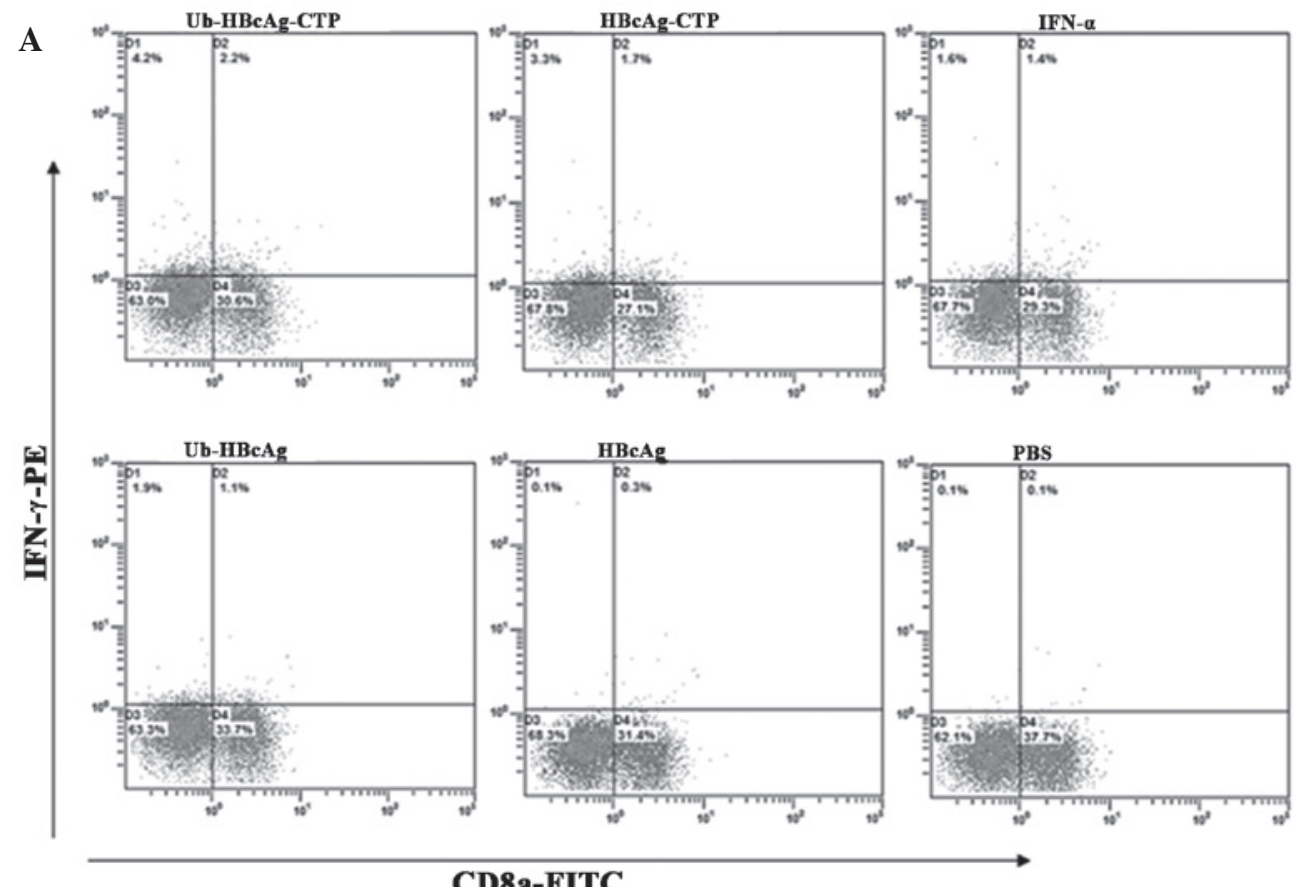

B

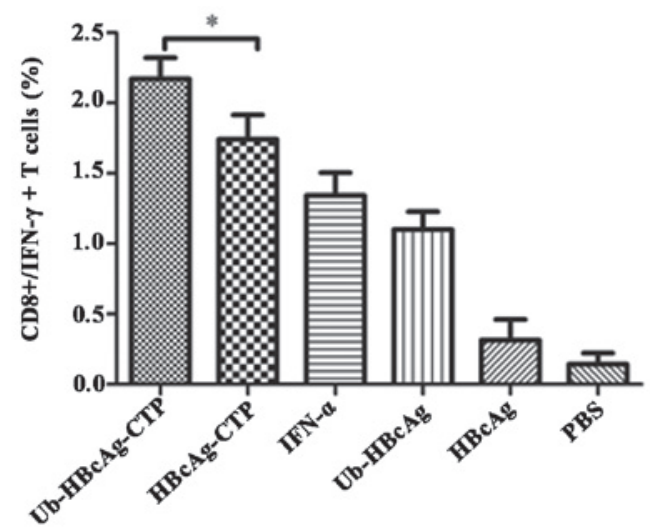

Figure 1. Intracellular cytokine expression in splenic lymphocytes of transgenic mice. (A) One week subsequent to the third immunization, mice were euthanized and splenic lymphocytes were isolated and re-stimulated in vitro by $\mathrm{HBcAg}$ for $3 \mathrm{~h}$, followed by addition of $25 \mu \mathrm{g} / \mathrm{ml} \mathrm{PMA}, 1 \mu \mathrm{g} / \mathrm{ml}$ ionomycin and $1.7 \mu \mathrm{g} / \mathrm{ml}$ monensin for an additional $3 \mathrm{~h}$. Re-stimulated T cells were stained with fluorescent FITC-CD8 $\alpha$ and PE-IFN- $\gamma$ antibodies, then the doubly stained cells were counted and analyzed by flow cytometry. (B) Values are expressed as the mean \pm standard deviation ( $\mathrm{n}=7$ ) and are representative of a minimum of three individual experiments. "P $<0.05$. HBcAg, hepatitis B core antigen; PMA, phorbol 12-myristate 13-acetate; FITC, fluorescein isothiocyanate; PE, phycoerythrin; IFN, interferon; Ub, ubiquitin; CTP, cytoplasmic transduction peptide; PBS, phosphate-buffered saline.

suggested that Ub-HBcAg-CTP induced specific CTL activity, in accordance with high IFN- $\gamma$ levels in $\mathrm{CD}^{+} \mathrm{T}$ cells.

$H B s A g, H B V D N A$ and $A L T$ in serum samples from $H B V$ transgenic mice. Subsequently, the virus clearance following immunization was evaluated using the fusion proteins. The serum HBV DNA load of transgenic mice was determined by quantitative PCR to assess the curative effect of HBV-derived epitope-specific $\mathrm{CD}^{+} \mathrm{T}$ cells at 1 week subsequent to the second and third immunizations, respectively. In parallel, serum HBsAg levels were detected at the same time-points. Of note, serum HBsAg levels were markedly reduced in the $\mathrm{Ub}-\mathrm{HBcAg-CTP}$ group compared with those in the other groups, including $\mathrm{HBcAg}-\mathrm{CTP}, \mathrm{Ub}-\mathrm{HBcAg}$ and IFN- $\alpha$, as presented in Fig. 3A ( $\left.{ }^{*} \mathrm{P}<0.05\right)$. Likewise, serum HBV DNA titers were significantly reduced in mice immunized with $\mathrm{Ub}-\mathrm{HBcAg-CTP}$, compared with those in the HBcAg-CTP,
Ub-HBcAg and IFN- $\alpha$ groups (Fig. 3B; ${ }^{*} \mathrm{P}<0.05$ ). These results suggested that specific $\mathrm{CD}^{+} \mathrm{T}$ cells induced by Ub-HBcAg-CTP produced IFN- $\gamma$, mediating the inhibition of HBV replication in HBV transgenic mice. Significant elevations in ALT levels were observed in serum samples from mice treated with Ub-HBcAg-CTP (Fig. 3C; ${ }^{\text {P }<0.05) . ~}$

Histopathological alterations. Liver tissue sections were evaluated primarily in terms of hepatocyte degeneration and necrosis in addition to lymphocyte infiltration. A larger number of lymphocytes appeared in the livers from mice immunized with Ub-HBcAg-CTP (Fig. 4A), compared with that in the other groups. To further confirm the therapeutic effects of the fusion proteins in transgenic mice, immunohistological analysis was conducted. While high quantities of HBsAg and HBcAg were observed (brownish yellow stain) in the cytoplasm of hepatocytes from PBS-treated mice, 
A

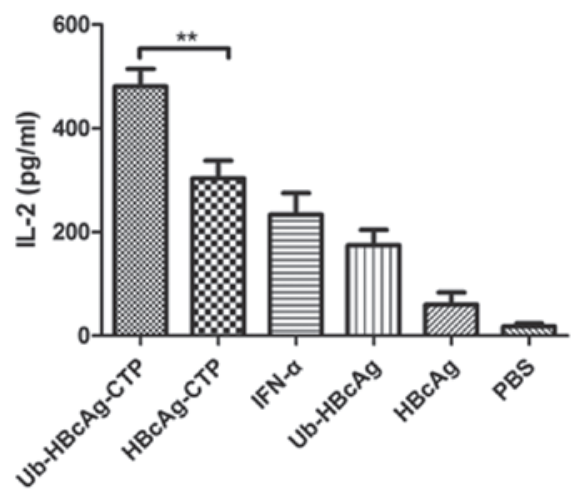

C

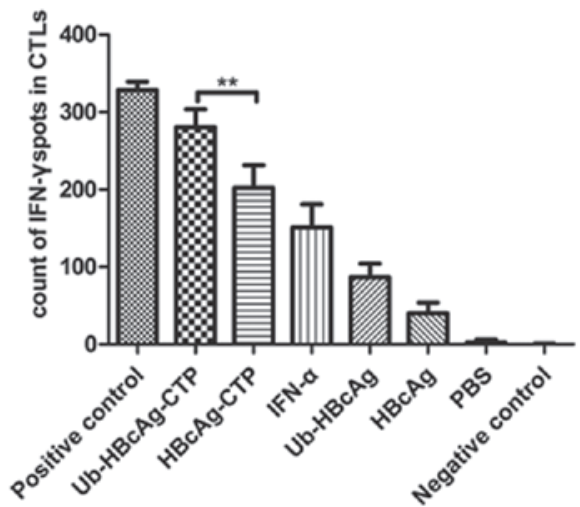

B

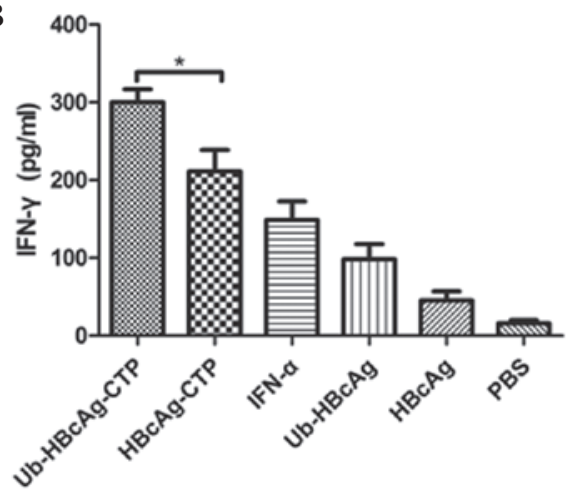

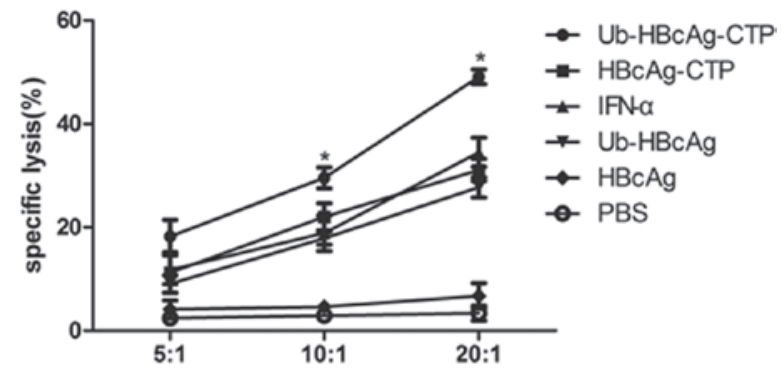

Figure 2. (A) IL-2 and (B) IFN- $\gamma$ were measured in splenic lymphocyte culture supernatants by ELISA. In addition, IFN- $\gamma$ spot numbers in CTLs were detected by an enzyme-linked immunospot assay. (C) The number of IFN- $\gamma$ spots from hepatitis B virus transgenic mice. (D) Specific CTL activity was measured by lactate dehydrogenase release. CTL activity is indicated as the mean percentage of specific lysis at different effector-to-target ratios. Values are expressed as the mean \pm standard deviation $(\mathrm{n}=7)$ and are representative of a minimum of three individual experiments. $\mathrm{P}<0.01$; ${ }^{\mathrm{P}}<0.05$, compared with the HBcAG-CTP IL-2, interleukin-2; IFN- $\gamma$, interferon- $\gamma$; CTL, cytotoxic T-lymphocyte; HBsAg, hepatitis B core antigen; Ub, ubiquitin; CTP, cytoplasmic transduction peptide; PBS, phosphate-buffered saline.

A

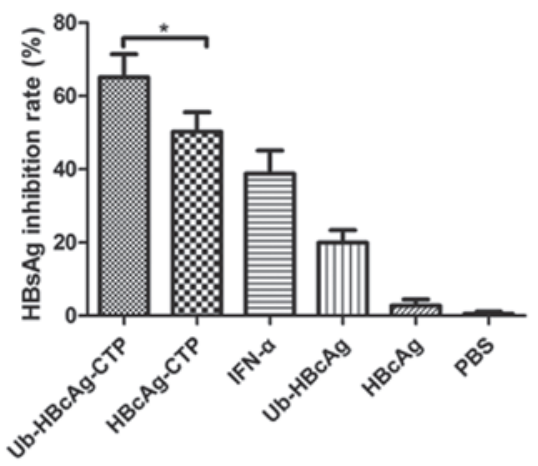

B

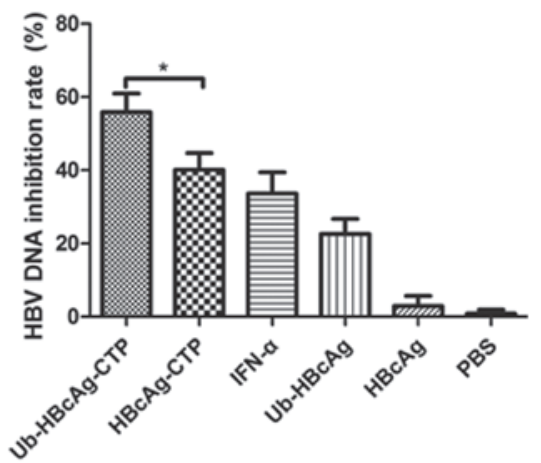

C

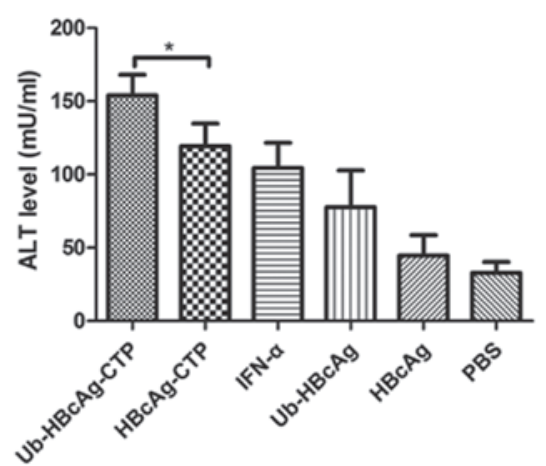

Figure 3. In vivo inhibitory effects on HBsAg, HBV DNA and ALT in HBV transgenic mice immunized with different fusion proteins. Mice were bled at 1 week following the second and third immunizations, respectively, and the levels of HBsAg and HBV DNA were quantified. (A) HBsAg and (B) HBV DNA inhibitory rates in serum samples from mice treated with different fusion proteins. (C) Mean levels ( $\mathrm{mU} / \mathrm{ml})$ of sALT in the six groups of mice were examined at 7 days subsequent to the third injection. Values are expressed as the mean \pm standard deviation $(n=7)$ and are representative of a minimum of three individual experiments. " $\mathrm{P}<0.05$. HBsAg, hepatitis B surface antigen; HBV, hepatitis B virus; sALT, serum alanine aminotransferase; IFN- $\alpha$, interferon- $\alpha$; Ub, ubiquitin; CTP, cytoplasmic transduction peptide; PBS, phosphate-buffered saline. 


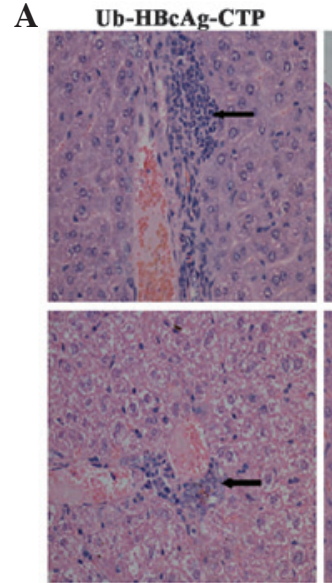

UbHBcAg

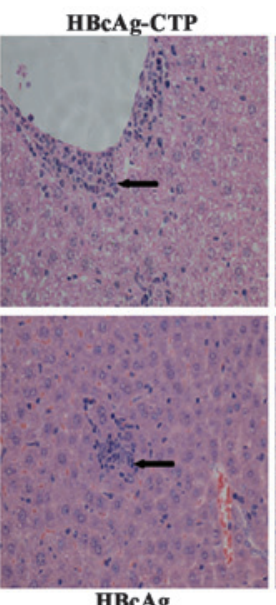

HBcAg

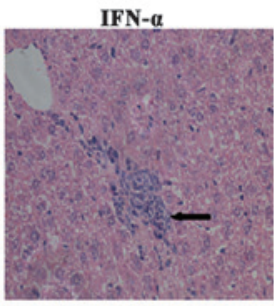

B
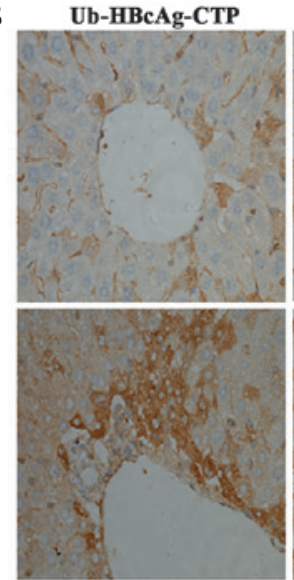

UbHBcAg
HBCAg-CTP
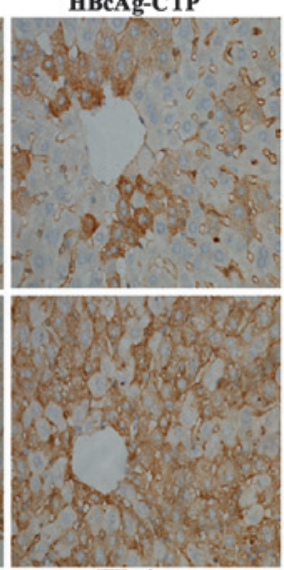

HBcAg
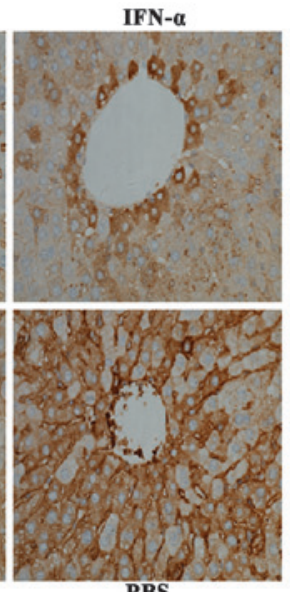
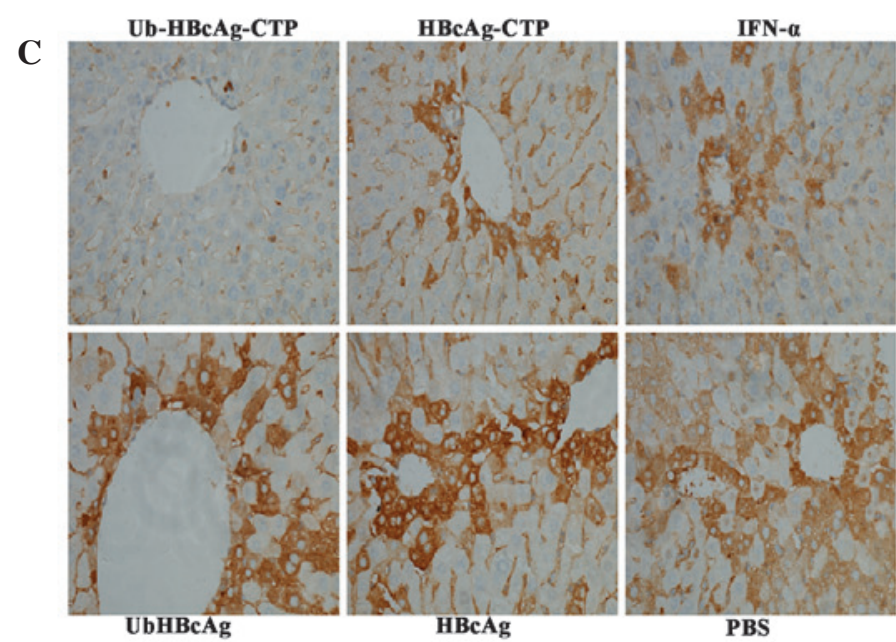

Figure 4. Histopathological alterations and immunohistological analysis of HBsAg and HBcAg in transgenic mouse livers. (A) Histological analysis of liver-infiltrating lymphocytes. Liver sections were stained with hematoxylin and eosin and were examined by light microscopy. A small number of lymphocytes appeared in mouse livers (indicated by arrows). Liver sections were subjected to immunohistological analysis for (B) HBsAg and (C) HBcAg detection, respectively (magnification, $\mathrm{x} 400$ ). HBsAg, hepatitis B surface antigen; HBcAg, hepatitis B core antigen; IFN- $\alpha$, interferon- $\alpha$; Ub, ubiquitin; CTP, cytoplasmic transduction peptide; PBS, phosphate-buffered saline.

they were not apparent in the Ub-HBcAg-CTP-treated group (Fig. 4B and C). Therefore, it was suggested that immunization with $\mathrm{Ub}-\mathrm{HBcAg}-\mathrm{CTP}$ reduced $\mathrm{HBsAg}$ and $\mathrm{HBcAg}$ levels, to a certain extent.

\section{Discussion}

Antigen-based immunotherapy (vaccine therapy) is considered a promising therapeutic strategy for $\mathrm{HBV}$ infections, controlling HBV replication in chronic hepatitis B by inducing Th1 immunity and enhancing $\mathrm{HBV}$-specific immune responses $(25,26)$. Therefore, a novel therapeutic vaccine (Ub-HBcAg-CTP) was designed for effective activation of Th1 immunity and the specific $\mathrm{CD}^{+} \mathrm{T}$ cell response, which should compensate for the deficient HBV-specific anti-viral immunity and would not be subject to functional exhaustion during chronic HBV infections.

In the present study, HBV transgenic mice whose hepatocytes replicated the virus at levels comparable to those observed in the livers of patients with chronic hepatitis and who had no evidence of cytopathology were used. This model enabled the assessment of the effects of viral and host factors on HBV pathogenesis and replication, and the evaluation of the anti-viral potential of pharmacological agents and physiological processes, including the immune response (20).

Efficient T-cell responses require $\mathrm{CD}^{+} \mathrm{T}$ cells to recognize antigenic peptides presented by MHC I molecules on the surface of APCs (predominantly DCs) (27). However, patients with chronic hepatitis B commonly display an immunocompromised immune tolerance with impaired DC function $(28,29)$. CTP, a novel transduction carrier, has been demonstrated to be efficient in the delivery of antigens into the cytoplasm of DCs (30). Therefore, CTP was used in the present study as a tool for efficient delivery of $\mathrm{Ub}$ and $\mathrm{HBcAg}$, thus boosting DC antigen-presenting capacities and inducing a greater number of $\mathrm{HBV}$-specific $\mathrm{CD}^{+} \mathrm{T}$ cells.

Defects in cytokine secretion of antigen-specific $\mathrm{CD}^{+}$ $\mathrm{T}$ cells have been previously associated with chronic HBV infection (31). Therefore, the induction of a strong, polyclonal, potent multifunctional $\mathrm{HBV}$-specific $\mathrm{CD}^{+} \mathrm{T}$-cell response is highly desirable, due to the fact that this would be able to trigger cytokine secretion. As mentioned above, CD8 ${ }^{+}$ $\mathrm{T}$ cells induced by $\mathrm{Ub}-\mathrm{HBcAg-CTP}$ vaccination were highly functional. Mice immunized with Ub-HBcAg-CTP exhibited significantly higher IFN- $\gamma$ and IL-2 (Th1-like) secretion and 
$\mathrm{HBcAg}$-specific $\mathrm{CD} 8^{+} / \mathrm{IFN}-\gamma^{+} \mathrm{T}$ cells in the spleen, compared with those in the other treatment groups. These observations indicated that the Thl dominant responses were associated with significant enhancement of CTL activity following Ub-HBcAg-CTP vaccination. Th1 immunity appears to be crucial for the induction of CTL leading to cytolytic effects, which are beneficial for viral or tumor eradication (32). Furthermore, the in vivo cytotoxicity data from the present study demonstrated that the higher magnitude of CTL response induced by Ub-HBcAg-CTP was correlated with an increase in cell death of HBcAg-derived peptide-loaded target cells (P815/c). Therefore, a complete response to anti-viral treatment was correlated with predominant Th1 responses accompanied with enhanced CTL activity in patients with chronic HBV or transgenic mice (33). This implied that activation of Thl immunity accompanied by efficient CTL activity subsequent to vaccination therapy is a common immune mechanism for successful treatment of hepatitis B (34).

It has been previously demonstrated that inadequate endogenous antigen presentation by MHC class I molecules to $\mathrm{CD}^{+} \mathrm{T}$ cells is one mechanism by which the immune system fails to eliminate HBV (35). Therefore, efficient elimination of virus-infected target cells by CTLs is only able to occur by rapid MHC class I antigen presentation of viral epitopes on the cell surface (36). Ub-HBcAg-CTP, with a modification for ubiquitin conjugation of antigen protein, exposes its $\mathrm{N}$-terminal residue ('the $\mathrm{N}$-end rule') $(37,38)$, which further facilitates ubiquitination. In this manner, a polyubiquitin chain is synthesized, which targets the protein for rapid degradation by the UPS (39). It was identified in the present study that the enhancement of Ub-antigen presentation increased the number of $\mathrm{HBcAg}$-specific $\mathrm{CD} 8^{+} / \mathrm{IFN}-\gamma^{+} \mathrm{T}$ cells in $\mathrm{Ub}-\mathrm{HBcAg}$-CTP immunized mice. This may be due to the fact that increased Ub-fused HBcAg is rapidly degraded by the UPS, which results in efficient production of a variety of peptides, including numerous CTL epitopes, which may be presented by multiple MHC class I molecules. Additional studies have demonstrated that rapidly ubiquitinated antigens are more rapidly presented on class I molecules and/or highly induced $(40,41)$.

The immunization of transgenic mice with Ub-HBcAg-CTP induced an efficient specific immune response and led to the control of viral replication. An increasing number of studies have demonstrated that secreted cytokines and activated CTLs may effectively downregulate HBV gene expression and additionally may control HBV replication $(23,42)$. At 1 week subsequent to the last immunization to HBV transgenic mice, the hepatocytes appeared to swell and exhibited hyperemia and lymphocyte infiltration in liver tissues from $\mathrm{Ub}-\mathrm{HBcAg}-\mathrm{CTP}$ animals. The inflammatory reactions in the livers were consistent with specific CTL activity induced by $\mathrm{Ub}-\mathrm{HBcAg}$-CTP. In addition, the results of the present study indicated that the fusion peptide significantly reduced serum HBsAg and HBV DNA levels in addition to the expression of $\mathrm{HBcAg}$ and HBsAg in the liver. This reduction was closely associated with Ub-HBcAg-CTP, suggesting that the observed therapeutic effects were associated with the enhanced immune responses. These observations demonstrated the potential of $\mathrm{Ub}-\mathrm{HBcAg}$-CTP to induce a stronger CTL response in transgenic mice than control vaccinations. Akbar et al (43) reported that the strong immunomodulatory capabilities of $\mathrm{HBcAg}$ may be due to an establishment of an inflammatory hepatic microenvironment, the induction of $\mathrm{HBcAg}$-specific CTL in the liver and the activation of host DCs. To further confirm the specific CTL activity in the liver, the levels of ALT were measured. In contrast with control animals, greater ALT levels were observed in $\mathrm{Ub}-\mathrm{HBcAg}-\mathrm{CTP}$ immunized mice, indicating that infected hepatocytes were eliminated by vaccination-induced cytotoxic $\mathrm{T}$ cells. Although the activation levels of $\mathrm{HBcAg}$-specific CTL in the liver were not assessed in the present study, the histological and serological alterations observed provided indirect support for the hypothesis that an anti-inflammatory hepatic microenvironment may be established in the Ub-HBcAg-CTP group. However, this remains to be confirmed in future studies.

In conclusion, the present study demonstrated that vaccination with Ub-HBcAg-CTP activated Th1 immunity, induced a robust and multifunctional HBcAg-specific T-cell response and provided a therapeutic effect in HBV transgenic mice. Therefore, a combination of Ub-HBcAg-CTP may be used as a potential therapeutic strategy for the treatment of chronic hepatitis B viral infections.

\section{Acknowledgements}

The present study was supported by the grants from the National Natural Science Foundation of China (grant no. 81270502).

\section{References}

1. Custer B, Sullivan SD, Hazlet TK, Iloeje U, Veenstra DL and Kowdley KV: Global epidemiology of hepatitis B virus. J Clin Gastroenterol 38: S158-S168, 2004.

2. Perz JF, Armstrong GL, Farrington LA, Hutin YJ and Bell BP: The contributions of hepatitis $B$ virus and hepatitis $C$ virus infections to cirrhosis and primary liver cancer worldwide. J Hepatol 45: 529-538, 2006.

3. Buchmann P, Dembek C, Kuklick L, et al: A novel therapeutic hepatitis B vaccine induces cellular and humoral immune responses and breaks tolerance in hepatitis B virus (HBV) transgenic mice. Vaccine 31: 1197-1203, 2013.

4. Rehermann B: Immune responses in hepatitis B virus infection. Semin Liver Dis 23: 21-38, 2003.

5. Baumert TF, Thimme R and Von Weizsacker F: Pathogenesis of hepatitis B virus infection. World J Gastroenterol 13: 82-90, 2007.

6. Thimme R, Wieland S, Steiger C, et al: CD8+ T cells mediate viral clearance and disease pathogenesis during acute hepatitis $\mathrm{B}$ virus infection. J Virol 77: 68-76, 2003.

7. Chen W, Shi M, Shi F, et al: HBcAg-pulsed dendritic cell vaccine induces Th1 polarization and production of hepatitis $B$ virus-specific cytotoxic T lymphocytes. Hepatol Res 39: 355-365, 2009.

8. Yang BF, Zhao HL, Xue C, et al: Recombinant heat shock protein 65 carrying hepatitis B core antigen induces $\mathrm{HBcAg}$-specific CTL response. Vaccine 25: 4478-4486, 2007.

9. Tang Y, Chen X, Zhang Y, et al: Fusion protein of tapasin and hepatitis B core antigen 18-27 enhances T helper cell type 1/2 cytokine ratio and antiviral immunity by inhibiting suppressors of cytokine signaling family members $1 / 3$ in hepatitis B virus transgenic mice. Mol Med Rep 9: 1171-1178, 2014.

10. Kim D, Jeon C, Kim JH, et al: Cytoplasmic transduction peptide (CTP): new approach for the delivery of biomolecules into cytoplasm in vitro and in vivo. Exp Cell Res 312: 1277-1288, 2006.

11. Song L, Zhuo M, Tang Y, Chen X, Yu Y, Tang Z, et al: Ubiquitin-modified hepatitis B virus core antigen effectively facilitates antigen presentation and enhances cytotoxic T lymphocyte activity via the cytoplasmic transduction peptide invitro. Mol Med Rep 12: 289-296, 2015.

12. Kerscher O, Felberbaum R and Hochstrasser M: Modification of proteins by ubiquitin and ubiquitin-like proteins. Annu Rev Cell Dev Biol 22: 159-180, 2006. 
13. Goldberg AL: Protein degradation and protection against misfolded or damaged proteins. Nature 426: 895-899, 2003.

14. Bandi P, Garcia ML, Booth CJ, Chisari FV and Robek MD: Bortezomib inhibits hepatitis $\mathrm{B}$ virus replication in transgenic mice. Antimicrob Agents Chemother 54: 749-756, 2010.

15. Loureiro J and Ploegh HL: Antigen Presentation and the ubiquitin-proteasome system in host-pathogen interactions. Adv Immunol 92: 225-305, 2006.

16. Kerscher O, Felberbaum R and Hochstrasser M: Modification of proteins by ubiquitin and ubiquitin-like proteins. Annu Rev Cell Dev Biol 22: 159-180, 2006.

17. Welchman RL, Gordon C and Mayer RJ: Ubiquitin and ubiquitin-like proteins as multifunctional signals. Nat Rev Mol Cell Biol 6: 599-609, 2005

18. Song L, Zhuo M, Tang Y, Chen X, Tang Z and Zang G. Ubiquitin-hepatitis B core antigen-cytoplasmic transduction peptide enhances HBV-specific humoral and CTL immune responses in vivo International Immunopharmacology 23: 1-7, 2014.

19. Chen JH, Yu YS, Chen XH, Liu HH, Zang GQ and Tang ZH: Enhancement of CTLs induced by DCs loaded with ubiquitinated hepatitis B virus core antigen. World J Gastroenterol 18 1319-1327, 2012.

20. Guidotti LG, Matzke B, Schaller H and Chisari FV: High-level hepatitis B virus replication in transgenic mice. J Virol 69: 6158-6169, 1995.

21. Crawford TQ, Ndhlovu LC, Tan A, et al: HIV-1 infection abrogates $\mathrm{CD} 8+\mathrm{T}$ cell mitogen-activated protein kinase signaling responses. J Virol 85: 12343-12350, 2011.

22. Lycke NY and Coico R: Measurement of immunoglobulin synthesis using the ELISPOT assay. Curr Protoc Immunol: 14, 2001.

23. Chen X, Lai J, Pan Q, Tang Z, Yu Y and Zang G: The delivery of $\mathrm{HBcAg}$ via Tat-PTD enhances specific immune response and inhibits Hepatitis B virus replication in transgenic mice. Vaccine 28: 3913-3919, 2010.

24. Huang Y, Chen Z, Jia H, Wu W, Zhong S and Zhou C: Induction of Tc1 response and enhanced cytotoxic T lymphocyte activity in mice by dendritic cells transduced with adenovirus expressing HBsAg. Clin Immunol 119: 280-290, 2006.

25. Boni C, Fisicaro P, Valdatta C, et al: Characterization of hepatitis B virus (HBV)-specific T-cell dysfunction in chronic HBV infection. J Virol 81: 4215-4225, 2007.

26. Deng Q, Mancini-Bourgine M, Zhang X, et al: Hepatitis B virus as a gene delivery vector activating foreign antigenic $\mathrm{T}$ cell response that abrogates viral expression in mouse models. Hepatology 50 $1380-1391,2009$

27. Neefjes J, Jongsma ML, Paul P and Bakke O: Towards a systems understanding of MHC class I and MHC class II antigen presentation. Nat Rev Immunol 11: 823-836, 2011.

28. Tavakoli S, Mederacke I, Herzog-Hauff S, et al: Peripheral blood dendritic cells are phenotypically and functionally intact in chronic hepatitis B virus (HBV) infection. Clin Exp Immunol 151: 61-70, 2008.
29. Op den Brouw ML, Binda RS, Van Roosmalen MH, et al: Hepatitis B virus surface antigen impairs myeloid dendritic cell function: a possible immune escape mechanism of hepatitis B virus. Immunology 126: 280-289, 2009.

30. Chen X, Liu H, Tang Z, Yu Y and Zang G: The modification of Tapasin enhances cytotoxic T lymphocyte activity of intracellularly delivered CTL epitopes via cytoplasmic transduction peptide. Acta Biochim Biophys Sin (Shanghai) 45: 203-212, 2013.

31. Das A, Hoare M, Davies N, et al: Functional skewing of the global CD8 T cell population in chronic hepatitis B virus infection. J Exp Med 205: 2111-2124, 2008.

32. Chamoto K, Kosaka A, Tsuji T, et al: Critical role of the Th1/Tc1 circuit for the generation of tumor-specific CTL during tumor eradication in vivo by Th1-cell therapy. Cancer Sci 94: 924-928, 2003.

33. Tsai SL, Sheen IS, Chien RN, et al: Activation of Th1 immunity is a common immune mechanism for the successful treatment of hepatitis B and C: tetramer assay and therapeutic implications. J Biomed Sci 10: 120-135, 2003.

34. Boni C, Bertoletti A, Penna A, et al: Lamivudine treatment can restore $\mathrm{T}$ cell responsiveness in chronic hepatitis B. J Clin Invest 102: 968-975, 1998.

35. Kosinska AD, Johrden L, Zhang E, et al: DNA prime-adenovirus boost immunization induces a vigorous and multifunctional T-cell response against hepadnaviral proteins in the mouse and woodchuck model. J Virol 86: 9297-9310, 2012.

36. Seifert U and Krüger E: Remodelling of the ubiquitin-proteasome system in response to interferons. Biochem Soc Trans 36: 879-884, 2008

37. Varshavsky A: The N-end rule. Cell 69: 725-735, 1992

38. Ciechanover A and Ben-Saadon R: N-terminal ubiquitination: more protein substrates join in. Trends Cell Biol 14: 103-106, 2004.

39. Rock KL and Goldberg AL: Degradation of cell proteins and the generation of MHC class I-presented peptides. Ann Rev Immunol 17: 739-779, 1999 .

40. Rodriguez F, Zhang J and Whitton JL: DNA immunization: ubiquitination of a viral protein enhances cytotoxic T-lymphocyte induction and antiviral protection but abrogates antibody induction. J Virol 71: 8497-8503, 1997.

41. Liu Y, Testa JS, Philip R, Block TM and Mehta AS: A ubiquitin independent degradation pathway utilized by a hepatitis B virus envelope protein to limit antigen presentation. PLoS One 6: e24477, 2011.

42. Roh S and Kim K: Overcoming tolerance in hepatitis B virus transgenic mice: a possible involvement of regulatory $\mathrm{T}$ cells. Microbiol Immunol 47: 453-460, 2003.

43. Akbar SM, Chen S, Al-Mahtab M, Abe M, Hiasa Y and Onji M: Strong and multi-antigen specific immunity by hepatitis B core antigen ( $\mathrm{HBcAg}$ )-based vaccines in a murine model of chronic hepatitis $\mathrm{B}: \mathrm{HBcAg}$ is a candidate for a therapeutic vaccine against hepatitis B virus. Antiviral Res 96: 59-64, 2012. 